Teresa Arozena Bonnet

Department of Fine Arts

Universidad de La Laguna

\section{Time Maps. Photography as the Display of Duration}

I recently realized that, as an artist, in deep, what I was always trying to do was to find how to solve a "communication conflict" or, to put it in other way, how to communicate complexity. That's really nothing new. The history of representation is the history of images created by man to understand and transmit life, the complex experience of the world. Artistic practices are always a tool of knowledge that deals with the Real, nothing less. Or, in other words, they are that procedure which frames the Real - understood as the unrepresentable, or as "what can not be said".

To find concepts, affects, values, to discover underlying structures in life, and communicate them. To represent reality, to build it over and over again. To propose it. This is the great play of forms, the waves of the cultural construct, that beat the beaches of the Real, the arena of complexity. There is no way to focus on art and not being in that arena.

In photography, in particular, complexity is often presented through the specific relationship that this medium professes with time. I am interested in an approach to time understood as one of the forms that takes Attention of and Relation.

Many authors who have dealt with specific forms of time in their photographic productions have developed their graphic research through the elements of grid, seriality and sequentiality (difference and repetition, or, "neither identical, nor different") as ways of expressing complexity.

Chrono-photography is an obvious example of this fact (here we have Marey, Muybridge, or Edgerton), but also narrative seriality in photography, or the so-called "cinematographic disassembly" of reality (i.e Allan Sekula), deals with these approximations to complexity through the Relation. Spatial installations in art, or what might be called "informational environments", often play a determining role in developing a network of semiotic links.

In my work I have often worried about how working these ideas. The early series of "El intruso" (2006) already contained the germen of a temporary and sequential search through the photographic support. The works that I present in this poster are two photographic installations developed in 2017, and exhibited at La Regenta Art Center, in Las Palmas de Gran Canaria, within the framework of an individual exhibition in June 2017. In both of them I use a method that I call stacking.

In this photographic installation I try to approach to a "phantom antrophology" (Bataille), which, starting from the real event, or, indeed, from the cultural event, expands towards the sphere of myth.

The method of stacking images, in this work follows the pattern of a Russian Doll (one image inside the other, successively) allows me to propose an approximation to the complexity of the temporal experience by recording and synthesizing different durations in the same static grid. I work without hierarchies, I mean I use both images made by myself along with found footage images taken of Canary history, with the aim of tracking a kind of DNA, trace or inheritance. The conception of seriality and repetition lie in the procedure but also in my subjects (crowd, social rite, entertainment, compulsion, devotion, tourism, merchandise). In this way I try to develop a kind of kaleidoscopic and mythological image-synthesis of my island.

This mythical dimension of the Real is revealed through the traces, the repetitive prints on the skin of photographic support. Are these traces that are automatically staked, almost as scars on the skin of the photographic support, which are revealing themselves the phantom behind things. 

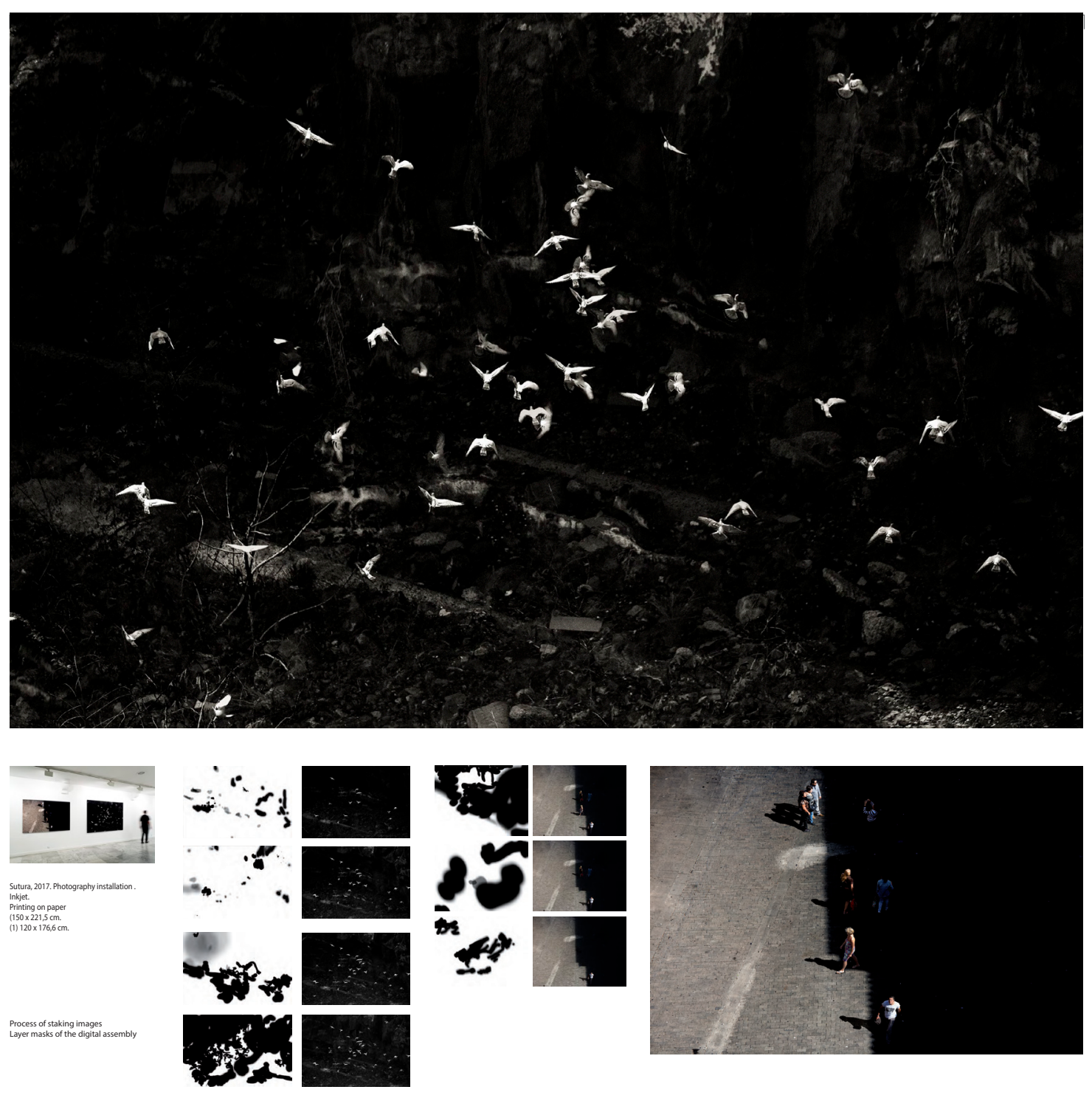